\title{
PACAP and its role in primary headaches
}

\author{
Lars Edvinsson ${ }^{1 *}$, János Tajti ${ }^{2}$ Levente Szalárdy ${ }^{2}$ and László Vécsei ${ }^{2,3}$
}

\begin{abstract}
Pituitary adenylate cyclase-activating peptide (PACAP) is a neuropeptide implicated in a wide range of functions, such as nociception and in primary headaches. Regarding its localization, PACAP has been observed in the sensory trigeminal ganglion (TG), in the parasympathetic sphenopalatine (SPG) and otic ganglia (OTG), and in the brainstem trigeminocervical complex. Immunohistochemistry has shown PACAP-38 in numerous cell bodies of SPG/OTG, co-stored with vasoactive intestinal peptide (VIP), nitric oxide synthase (NOS) and, to a minor degree, with choline acetyltransferase. PACAP has in addition been found in a subpopulation of calcitonin gene-related peptide (CGRP)immunoreactive cells in the trigeminal system. The PACAPNIP receptors $\left(P A C_{1}, V P A C_{1}\right.$, and $\left.V P A C_{2}\right)$ are present in sensory neurons and in vascular smooth muscle related to the trigeminovascular system. It is postulated that PACAP is involved in nociception. In support, abolishment of PACAP synthesis or reception leads to diminished pain responses, whereas systemic PACAP-38 infusion triggers pain behavior in animals and delayed migraine-like attacks in migraine patients without marked vasodilatory effects. In addition, increased plasma levels have been documented in acute migraine attacks and in cluster headache, in accordance with findings in experimental models of trigeminal activation. This suggest that the activation of the trigeminal system may result in elevated venous levels of PACAP, a change that can be reduced when headache is treated. The data presented in this review indicate that PACAP and its receptors may be promising targets for migraine therapeutics.
\end{abstract}

Keywords: PACAP, CGRP, Receptors, Migraine, Cluster headache

\section{Background}

The field of PACAP and its receptor $\mathrm{PAC}_{1}$ is currently very topical in the migraine field. Here we have provided an overview of available data bases; we used PubMed, Medline and Google Schoolar as sources. We report that PACAP is released in conjunction of migraine and cluster headache attacks. The most likely source of PACAP contributing to this elevation in cranial outflow resides in the trigeminovascular system (TVS) and the parasympathetic otic and sphenopalatine ganglia. The $\mathrm{PAC}_{1}$ receptor is less well described in the TVS, but found in the trigeminal and sphenopalatine ganglia. It is hypothesized that this may be a second neuropeptide system that might be useful to block in acute attacks.

\section{Introduction}

Migraine is thought to involve a primary dysregulation of sensory processing in the central nervous system

\footnotetext{
* Correspondence: lars.edvinsson@med.lu.se

'Department of Medicine, Institute of Clinical Sciences, Lund University, 221

84 Lund, Sweden

Full list of author information is available at the end of the article
}

(CNS) as a starting point of migraine [1]. It is thought that the origin of the disease rests in the hypothalamus - thalamus system, coupling to the brainstem. The central involvement is reflected early in many patients experiencing tactile allodynia and other neurological symptoms that affect the senses, including sensitivity to light, sound, and smell. These are thought to be consequences of central sensitization within the trigeminothalamic pathway. The trigeminovascular system is involved with all its parts; the trigeminal nerve, the cranial vasculature, and nuclei within the brainstem/spinal cord.

Pituitary adenylate cyclase-activating polypeptide (PACAP) and vasoactive intestinal peptide (VIP) are members of the VIP/secretin/growth hormone-releasing hormone/glucagon neuropeptide superfamily, widely expressed in vertebrate tissues [2-6]. VIP was first described by Victor Mutt during the early 1970s [7]. It was isolated from pig intestine and is localized to most organs and tissues in the body. During the following years, the other members of the family were described and characterized, including peptide histidine isoleucine/methionine (PHI/PHM), secretin, and PACAP $[3,8,9]$. The 
PACAP neuropeptide was discovered nearly 30 years ago based on its ability to enhance adenylate cyclase activity in rat pituitary cells, and was first isolated from ovine hypothalamic extracts [10]. Numerous studies on the localization/distribution/release of this group of neuropeptides from different tissues and involvement in diseases have been presented $[11,12]$. The aim of this review is to focus on sensory aspects of PACAP and primary headaches, with special emphasis on migraine.

\section{General features and localization of PACAP within the CNS}

There are two forms of PACAP (- 27 and - 38), with both isoforms sharing functional and structural homologies with VIP [10] and being able to bind to G-protein-coupled receptors specific $\left(\mathrm{PAC}_{1}\right)$ and less specific $\left(\mathrm{VPAC}_{1}\right.$ and $\mathrm{VPAC}_{2}$; with comparable affinity to VIP, PACAP-27, and PACAP-38) to PACAP [3, 13, 14]. Recently, however, the functional presence of yet unidentified PACAP receptors have been proposed based on experimental results using selective modulators [15].

PACAP is a pleiotropic peptide that can be found in several exocrine and endocrine tissues, in the respiratory, intestinal, urinary, and reproductive systems, as well as in the central and peripheral nervous systems [16-23]. In neuronal tissues, the isoform PACAP-38 predominates. It is known to play hypophysiotropic, neuromodulatory, and neurotransmitter roles, and has been associated with differentiation- and proliferation-inducing effects in the developing nervous system, as well as with cytoprotective, anti-apoptotic, and anti-inflammatory features within various target organs [24-34]. Furthermore, PACAP has been shown to be a potent local and systemic vasodilator administered in a wide concentration range, associating with biphasic paradoxical hypertensive effects in very large doses [35-37].

Immunohistochemical evidence confirms the presence of PACAP in anatomical structures relevant to the pathogenesis of primary headaches including migraine, such as in the trigeminocervical system, including nerve fibers in the dura mater, the cerebral vessels [38], the facial skin [39], the trigeminal ganglion (TG) [15, 39-44], the trigeminal nucleus caudalis (TNC) $[15,16,45]$, the Rexed 1 and 2 laminae at the C1-C2 levels of the cervical spinal cord [45] and in various brainstem nuclei within the 'migraine generator area' $[16,46,47]$ as well as in the parasympathetic sphenopalatine (SPG) and otic ganglia (OTG) [40, 41, 48-50]. Recent works have revealed that PACAP is localized in small neurons in the dorsal root ganglia and the TG which in addition store calcitonin gene-related peptide (CGRP) [44]. Interestingly PACAP mRNA-labeled neurons constituted $10 \%$ of the total number of nerve cell bodies in the dorsal root ganglia, whereas the population of CGRP mRNA-labeled nerve cell bodies constituted
46\% [51]. This agrees well with later in depth immunocytochemistry work on the TG [52] (Fig. 1).

In line with the above, early studies revealed the presence of specific PACAP-binding sites in relevant regions of the rat and human CNS [53, 54]. In addition, subsequent immunohistochemical and biochemical evidence demonstrated the presence of $\mathrm{PAC}_{1}$ and $\mathrm{VPAC}_{2}$ receptors in the rat TG [55]. Of note, there exist some discordant results, functional [56] and biochemical data on the mRNA level suggest that $\mathrm{VPAC}_{\mathbf{1}}$ receptors are not present in the TG of rats [55]. However, mRNA for all three types of VIP/PACAP receptors have been reported to occur in human and rat TG [57], and this is supported by another study in rat TG and TNC [15]. Moreover, protein expression has been shown by immunohistochemistry for all three types of PACAP receptors in both the human and rat SPG [49]. The evidence suggest a special role in terms of disease pathogenesis among relevant neuropeptides. The detailed histochemistry revealed that while VIP/ PACAP are both seen in the parasympathetic ganglia (SPG/OTG), only PACAP has been found in the trigeminal system [42].

\section{Early findings of neuropeptide release in primary headaches}

The role of PACAP and VIP is under discussion because (i) they appear jointly in most of the SPG/OTG neurons and (ii) PACAP co-localizes with CGRP only in a small fraction of neurons within the TG in the small to medium sized neurons. Early studies showed that in migraine VIP was only released in a subpopulation of patients that had facial symptoms such as nasal congestion, rhinorrhea, and scleral injection in addition to headache (probably due to the activation of the parasympathetic system). Importantly, all cluster headache subjects showed both facial symptoms and VIP release [58]; however, at that time, the methodology to measure PACAP was not available. We suggested that this was due to activation of the parasympathetic system. Experimental studies in cats [59] revealed that the activation of the trigeminal system may in addition involve the parasympathetic system, as denervation of the trigeminal nerve aborted the activation of SPG, interpreted either as a direct or indirect coupling between these two systems.

\section{Involvement of PACAP in migraine \\ Conclusions from the studies with PACAP infusion and knockouts}

Human provocation studies of migraine using systemic administration of different molecules have generated important insights into the possible mechanisms in primary headache diseases. CGRP, VIP, and PACAP-38 are all strong vasodilators, sharing the activation of adenylate 

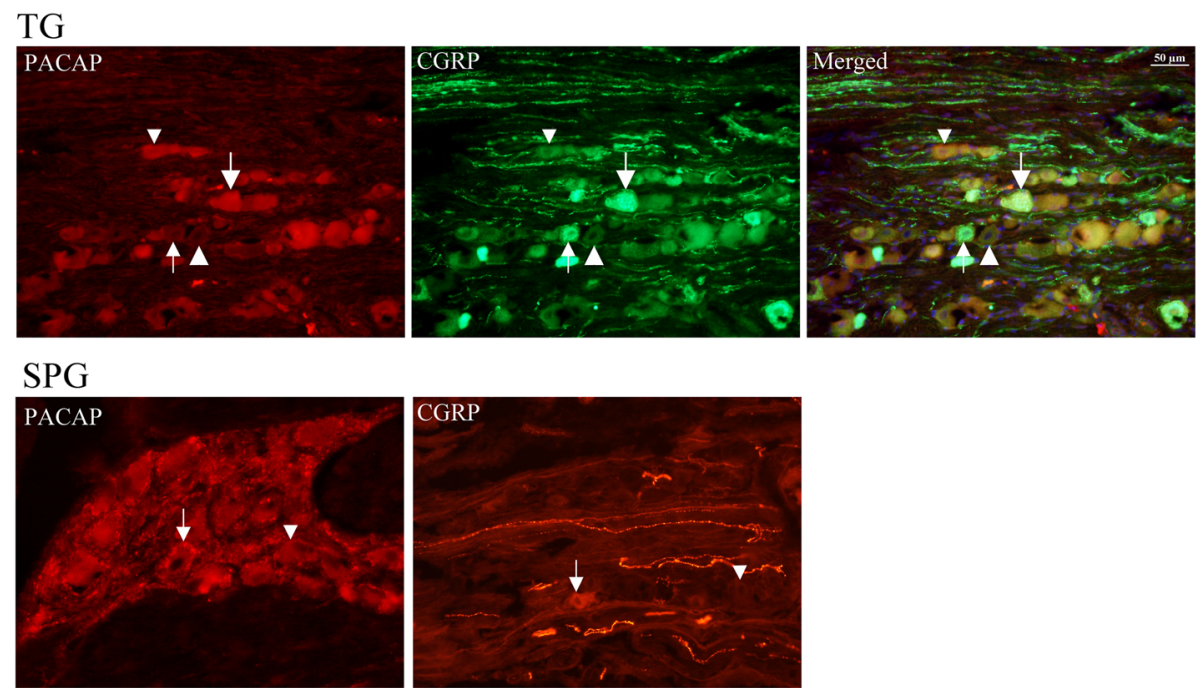

Fig. $1 \mathrm{Imm}$ unohistochemical demonstration of distribution of PACAP and CGRP in the sphenopalatine ganglion (SPG) and the trigeminal ganglion (TG). The figures illustrates that in both ganglia there are cells storing the two neuropeptides and also being alone. The CGRP immunoreactivity occurs more frequent in the TG than does PACAP-ir. Arrows show CGRP positive and PACAP negative cells, while arrow heads show co-localization (above) or negative (below). There are also fibers positive to CGRP. In the SPG the arrow shows a single CGRP positive cell that co-localize PACAP while numerous cells are positive to PACAP only (arrow head). In the right hand SPG illustration there are several CGRP positive fibers

cyclase. The first direct evidence that highlighted the potential significance of PACAP in the pathophysiology of migraine came from observations made in a human study [60] where intravenous administration of PACAP-38 caused headache and vasodilation in healthy subjects as well as in migraineurs, and lead to delayed-type migraine-like attacks exclusively in migraine patients without aura $(65-75 \%)$, a feature remarkably similar to that previously reported after nitroglycerin infusion [61, 62]. Because VIP had no such effect, it was suggested that this might be secondary to the activation of the $\mathrm{PAC}_{1}$ receptor, which is now under study in a clinical trial. For comparison, CGRP induces delayed migraine-like attacks in $65 \%$ of migraine patients, but not in normal subjects [63]. Today numerous CGRP active agents are on the verge of going to the market as effective therapy both for acute treatment and as prophylaxis.

In support of the above, a magnetic resonance imaging (MRI) angiographic study revealed that PACAP-38induced headache was associated with significant dilation of the extracranial part of the middle meningeal arteries (MMAs), but not of the middle cerebral arteries (MCAs). This effect preceded the onset of migraine-like headache and was sensitive to the administration of a triptan class of drug [64]. A subsequent MRI angiographic human study demonstrated a remarkable and sustained vasodilation of extracranial but not intracranial arteries (including the MCAs) following PACAP-38 administration [65]. In addition to these, intravenous PACAP-38-induced migraine-like attacks have been found associated with alterations in brain network connectivity, by means of a resting-state functional MRI study [66]. The role of VIP in PACAP-induced vasodilation is unclear, as data regarding its levels after PACAP administration are contradictory $[65,67]$, and its vasodilation is less long-lasting than that of PACAP [65]. The migraine response to PACAP-38 has not been found to be influenced by the presence of the risk allele MEF2D [67, 68].

Experimental studies support the relevance of PACAP in sensory functions as well as in pain disorders, including primary headaches. Neurograms obtained following stimulation of the ipsilateral peroneal or sciatic nerve suggested that intrathecal PACAP may act as a neurotransmitter or modulator in sensory C-fibers, possibly with a contribution of A-fibers [69]. Interestingly, PACAP-27 was more potent than PACAP-38 or VIP at this function. On the other hand, the direct intrathecal administration of PACAP elicited a dose-dependent decrease in the tail-flick latency, whereas higher doses resulted in biting and scratching; these behaviors were interpreted as pain-like syndrome and supported a role of PACAP as a sensory neurotransmitter involved in nociception [70]. Intrathecal administration of PACAP(6-38), a $\mathrm{PAC}_{1}$ receptor antagonist reduced mechanical and thermal hyperalgesia, suggesting that these receptors are important for PACAP-induced pain [71]. The role of $\mathrm{PAC}_{1}$ receptor in pain sensation has also been supported by studies using $\mathrm{PAC}_{1}$ knockout mice, as these animals showed reduced chronic 
responses to chemical, mechanical, and thermal stimuli $[72,73]$. Similar results were obtained with PACAPknockout mice, presenting with diminished lightaversive behavior (i.e., photophobia), decreased c-fos expression in the TNC and TG, and reduced meningeal blood flow following nitroglycerin administration compared to wild-type controls [74].

PACAP has also been implicated in higher order processing of pain in brain regions such as thalamus and amygdala [75, 76], relevant in the central sensitization and emotional load of pain. Intracerebroventricularly applied $\mathrm{PAC}_{\mathbf{1}}$ receptor inhibitor decreased the delayed activation and sensitization of second-order nociceptive neurons within the trigeminocervical complex following dural stimulation [77]. This supports a potential role of PACAP in the development of central sensitization of pain in migraine. There are experimental results suggesting the role of PACAP in the development of peripheral sensitization as well in certain models of pain [78]. The data on the possible role of PACAP and its receptors in migraine pathogenesis by means of modulating neurogenic inflammation [73, 79-81] and mast cell degranulation $[65,82-86]$ are, however, conflicting.

\section{PACAP as a biomarker in primary headaches}

A support for a sensory role of PACAP in nociception came from experiments with capsaicin administration in vivo in rats [26], as it resulted in elevated cerebrospinal fluid concentrations of PACAP-27 by 177\%, PACAP-38 by $93 \%$, and CGRP by $692 \%$ [87]. Studies on animal models of trigeminal activation confirm the potential role of PACAP in the pathogenesis of migraine in particular, as immunoreactivity of both PACAP-27 and PACAP-38 were found elevated in the TNC of rats following electrical stimulation (at the TG) or chemical stimulation (by nitroglycerin) of the trigeminovascular system [88]. Furthermore, PACAP-38 levels were found elevated in the blood plasma of rats after electrical stimulation of the TG [88]. Likewise, elevated levels of PACAP were measured in the external jugular vein samples of cats following electrical stimulation of the superior sagittal sinus [89]. In fact, stimulation of the trigeminal system directly showed the release of not only PACAP but also VIP and CGRP into the external jugular venous blood $[89,90]$.

Human clinical studies provide concordant data, as of note, elevated levels of plasma PACAP-38 were revealed in the ictal period of migraineurs (i.e., during a spontaneous migraine attack) compared to the interictal phase $[89,91]$. Interestingly, supportive data were reported in episodic cluster headache patients as well [92]. The interictal plasma PACAP concentrations of migraineurs were, however, significantly lower compared to the levels measured in healthy controls or in patients with tension-type headache [89, 91, 93].

\section{Concluding remarks}

The exact role of PACAP in primary headaches is still unknown but it is clearly present in many different parts of the CNS including several regions of interest in the discussions of migraine pathophysiology. Current evidence suggest that PACAP plays essential roles in the pathogenesis of migraine via modulating the function of nociceptive neurons within the trigeminocervical system.

The position of PACAP in migraine rests on the following main observations: (i) PACAP levels are increased in the circulation of cats and rats upon stimulation of the superior sagittal sinus $[89,94]$, and the TG, respectively [88]. (ii) PACAP levels in the external jugular vein are reduced with amelioration of migraine headache when subjects were treated with sumatriptan, and lower levels of PACAP occur between attacks when compared with attacks [89]. (iii) Systemic infusion of PACAP-38 in migraine patients results in migraine-like headache [60]. (iv) The plasma levels of PACAP-38 are altered in ictal and interictal periods of migraine patients [91]. The unanswered questions that remain are related to the origin of endogenous PACAP and the mechanism through which systemic PACAP can induce migraine. Though Banks suggests that PACAP has actions in the CNS and provides evidence in support [95], the available data strongly indicate that PACAP does not pass the wall of cerebral arteries, as studied in isolated perfused MCAs [96], which agrees with the view that the peptide is a large molecule that does not pass the blood-brain barrier (BBB) [96, 97]. Therefore, as suggested also for CGRP, the relevant target of systemically administered PACAP could very well be effects on sites located outside the BBB, such as the TG and other ganglia as well as the dura mater; however, this is still not settled, and the role of the $\mathrm{BBB}$ needs to be clarified.

\section{Conclusions}

1. The concordant experimental and clinical data show that PACAP and its receptors may have a role in the pathogenesis of primary headaches, especially migraine and cluster headache.

2. The relation with other neuronal messenger molecules deserves future study.

3. Collectively the current understanding of PACAP and its receptors in relation intracranial structures and brain provide valuable information as potential targets of effective future therapeutics. 
2013-Innovation; Grant No. 602633; GINOP-2.3.2-15-2016-00034, KTIA_NAP_13-2014-0022, GINOP-2.3.2-15-2016-00048, the MTA-SZTE Neuroscience Research Group.

\section{Ethical approval and consent to participate}

Not applicable.

\section{Availability of data and materials}

Not applicable.

\section{Authors' contributions}

All authors read and approved the final manuscript.

\section{Consent for publication}

Not applicable.

\section{Competing interests}

The author declares no competing interests.

\section{Competing interests}

Not applicable.

\section{Publisher's Note}

Springer Nature remains neutral with regard to jurisdictional claims in published maps and institutional affiliations.

\section{Author details}

${ }^{1}$ Department of Medicine, Institute of Clinical Sciences, Lund University, 221 84 Lund, Sweden. ${ }^{2}$ Department of Neurology, Faculty of Medicine, Albert Szent-Györgyi Clinical Center, University of Szeged, Semmelweis u. 6, Szeged H-6725, Hungary. ${ }^{3}$ MTA-SZTE Neuroscience Research Group, University of Szeged, Semmelweis u. 6, Szeged H-6725, Hungary.

\section{Received: 6 November 2017 Accepted: 28 February 2018} Published online: 09 March 2018

\section{References}

1. Schulte LH, May A (2016) The migraine generator revisited: continuous scanning of the migraine cycle over 30 days and three spontaneous attacks. Brain 139:1987-1993

2. Arimura A (2007) PACAP: the road to discovery. Peptides 28:1617-1619

3. Vaudry D, Falluel-Morel A, Bourgault S, Basille M, Burel D, Wurtz O, Fournie A, Chow BK, Hashimoto H, Galas L, Vaudry H (2009) Pituitary adenylate cyclase-activating polypeptide and its receptors: 20 years after the discovery. Pharmacol Rev 61:283-357

4. Alexandre D, Anouar Y, Jegou S, Fournier A, Vaudry H (1999) A cloned frog vasoactive intestinal polypeptide/pituitary adenylate cyclase-activating polypeptide receptor exhibits pharmacological and tissue distribution characteristics of both VPAC1 and VPAC2 receptors in mammals. Endocrinology 140:1285-1293

5. Wong AO, Leung MY, Shea WL, Tse LY, Chang JP, Chow BK (1998) Hypophysiotropic action of pituitary adenylate cyclase-activating polypeptide (PACAP) in the goldfish: immunohistochemical demonstration of PACAP in the pituitary, PACAP stimulation of growth hormone release from pituitary cells, and molecular cloning of pituitary type I PACAP receptor. Endocrinology 139:3465-3479

6. Nowak JZ, Zawilska JB (2003) PACAP in avians: origin, occurrence, and receptors-pharmacological and functional considerations. Curr Pharm Des 9:467-481

7. Mutt V, Said SI (1974) Structure of the porcine vasoactive intestinal octacosapeptide. The amino-acid sequence. Use of kallikrein in its determination. Eur J Biochem 42:581-589

8. Bataille D, Gespach C, Laburthe M, Amiranoff B, Tatemoto K, Vauclin N, Mutt $\checkmark$, Rosselin G (1980) Porcine peptide having N-terminal histidine and Cterminal isoleucine amide (PHI): vasoactive intestinal peptide (VIP) and secretin-like effects in different tissues from the rat. FEBS Lett 114:240-242

9. Zhou ZC, Gardner JD, Jensen RT (1989) Interaction of peptides related to VIP and secretin with Guinea pig pancreatic acini. Am J Phys 256: G283-G290

10. Miyata A, Arimura A, Dahl RR, Minamino N, Uehara A, Jiang L, Culler MD, Coy DH (1989) Isolation of a novel 38 residue-hypothalamic polypeptide which stimulates adenylate cyclase in pituitary cells. Biochem Biophys Res Commun 164:567-574

11. Uddman R, Malm L, Sundler F (1980) The origin of vasoactive intestinal polypeptide (VIP) nerves in the feline nasal mucosa. Acta Otolaryngol 89:152-156

12. Grunditz T, Hakanson R, Hedge G, Rerup C, Sundler F, Uddman R (1986) Peptide histidine isoleucine amide stimulates thyroid hormone secretion and coexists with vasoactive intestinal polypeptide in intrathyroid nerve fibers from laryngeal ganglia. Endocrinology 118:783-790

13. Laburthe M, Couvineau A, Tan V (2007) Class II G protein-coupled receptors for VIP and PACAP: structure, models of activation and pharmacology. Peptides 28:1631-1639

14. Schytz HW, Olesen J, Ashina M (2010) The PACAP receptor: a novel target for migraine treatment. Neurotherapeutics 7:191-196

15. Jansen-Olesen I, Baun M, Amrutkar DV, Ramachandran R, Christophersen DV Olesen J (2014) PACAP-38 but not VIP induces release of CGRP from trigeminal nucleus caudalis via a receptor distinct from the PAC1 receptor. Neuropeptides 48:53-64

16. Palkovits M, Somogyvari-Vigh A, Arimura A (1995) Concentrations of pituitary adenylate cyclase activating polypeptide (PACAP) in human brain nuclei. Brain Res 699:116-120

17. Masuo Y, Ohtaki T, Masuda Y, Tsuda M, Fujino M (1992) Binding sites for pituitary adenylate cyclase activating polypeptide (PACAP): comparison with vasoactive intestinal polypeptide (VIP) binding site localization in rat brain sections. Brain Res 575:113-123

18. Fahrenkrug J, Hannibal J (2011) Localisation of the neuropeptide PACAP and its receptors in the rat parathyroid and thyroid glands. Gen Comp Endocrinol 171:105-113

19. Koves K, Kantor O, Scammell JG, Arimura A (1998) PACAP colocalizes with luteinizing and follicle-stimulating hormone immunoreactivities in the anterior lobe of the pituitary gland. Peptides 19:1069-1072

20. Borzsei R, Mark L, Tamas A, Bagoly T, Bay C, Csanaky K, Banki E, Kiss P, Vaczy A, Horvath G, Nemeth J, Szauer E, Helyes Z, Reglodi D (2009) Presence of pituitary adenylate cyclase activating polypeptide-38 in human plasma and milk. Eur J Endocrinol 160:561-565

21. Moody TW, Ito T, Osefo N, Jensen RT (2011) VIP and PACAP: recent insights into their functions/roles in physiology and disease from molecular and genetic studies. Curr Opin Endocrinol Diabetes Obes 18:61-67

22. Barberi M, Muciaccia B, Morelli MB, Stefanini M, Cecconi S, Canipari R (2007) Expression localisation and functional activity of pituitary adenylate cyclaseactivating polypeptide, vasoactive intestinal polypeptide and their receptors in mouse ovary. Reproduction 134:281-292

23. Masuo Y, Tokito F, Matsumoto Y, Shimamoto N, Fujino M (1994) Ontogeny of pituitary adenylate cyclase-activating polypeptide (PACAP) and its binding sites in the rat brain. Neurosci Lett 170:43-46

24. Koves K, Arimura A, Somogyvari-Vigh A, Vigh S, Miller J (1990) Immunohistochemical demonstration of a novel hypothalamic peptide, pituitary adenylate cyclase-activating polypeptide, in the ovine hypothalamus. Endocrinology 127:264-271

25. Hashimoto H, Shintani N, Tanida M, Hayata A, Hashimoto R, Baba A (2011) PACAP is implicated in the stress axes. Curr Pharm Des 17:985-989

26. Reglodi D, Kiss P, Lubics A, Tamas A (2011) Review on the protective effects of PACAP in models of neurodegenerative diseases in vitro and in vivo. Curr Pharm Des 17:962-972

27. Seaborn T, Masmoudi-Kouli O, Fournier A, Vaudry H, Vaudry D (2011) Protective effects of pituitary adenylate cyclase-activating polypeptide (PACAP) against apoptosis. Curr Pharm Des 17:204-214

28. Ohtsuka M, Fukumitsu H, Furukawa S (2008) PACAP decides neuronal laminar fate via PKA signaling in the developing cerebral cortex. Biochem Biophys Res Commun 369:1144-1149

29. Watanabe J, Nakamachi T, Matsuno R, Hayashi D, Nakamura M, Kikuyama S, Nakajo S, Shioda S (2007) Localization, characterization and function of pituitary adenylate cyclase-activating polypeptide during brain development. Peptides 28:1713-1719

30. Reglodi D, Kiss P, Horvath G, Lubics A, Laszlo E, Tamas A, Racz B, Szakaly P (2012) Effects of pituitary adenylate cyclase activating polypeptide in the urinary system, with special emphasis on its protective effects in the kidney Neuropeptides 46:61-70

31. Ferencz A, Weber G, Helyes Z, Hashimoto H, Baba A, Reglodi D (2010) Presence of endogenous PACAP-38 ameliorated intestinal cold preservation tissue injury. J Mol Neurosci 42:428-434 
32. Racz B, Reglodi D, Horvath G, Szigeti A, Balatonyi B, Roth E, Weber G, Alotti N, Toth G, Gasz B (2010) Protective effect of PACAP against doxorubicin-induced cell death in cardiomyocyte culture. J Mol Neurosci 42:419-427

33. Elekes K, Sandor K, Moricz A, Kereskai L, Kemeny A, Szoke E, Perkecz A, Reglodi D, Hashimoto H, Pinter E, Szolcsanyi J, Helyes Z (2011) Pituitary adenylate cyclase-activating polypeptide plays an anti-inflammatory role in endotoxin-induced airway inflammation: in vivo study with gene-deleted mice. Peptides 32:1439-1446

34. Zhou CJ, Shioda S, Yada T, Inagaki N, Pleasure SJ, Kikuyama S (2002) PACAP and its receptors exert pleiotropic effects in the nervous system by activating multiple signaling pathways. Curr Protein Pept Sci 3:423-439

35. Warren JB, Cockcroft JR, Larkin SW, Kajekar R, Macrae A, Ghatei MA, Bloom SR (1992) Pituitary adenylate cyclase activating polypeptide is a potent vasodilator in humans. J Cardiovasc Pharmacol 20:83-87

36. Ishizuka Y, Kashimoto K, Mochizuki T, Sato K, Ohshima K, Yanaihara N (1992) Cardiovascular and respiratory actions of pituitary adenylate cyclaseactivating polypeptides. Regul Pept 40:29-39

37. Naruse S, Suzuki T, Ozaki T, Nokihara K (1993) Vasodilator effect of pituitary adenylate cyclase activating polypeptide (PACAP) on femoral blood flow in dogs. Peptides 14:505-510

38. Eftekhari S, Warfvinge K, Blixt FW, Edvinsson L (2013) Differentiation of nerve fibers storing CGRP and CGRP receptors in the peripheral trigeminovascular system. J Pain 14:1289-1303

39. Moller K, Zhang YZ, Hakanson R, Luts A, Sjolund B, Uddman R, Sundler F (1993) Pituitary adenylate cyclase activating peptide is a sensory neuropeptide: immunocytochemical and immunochemical evidence. Neuroscience 57:725-732

40. Baeres FM, Moller M (2004) Origin of PACAP-immunoreactive nerve fibers innervating the subarachnoidal blood vessels of the rat brain. J Cereb Blood Flow Metab 24:628-635

41. Nielsen HS, Hannibal J, Fahrenkrug J (1998) Embryonic expression of pituitary adenylate cyclase-activating polypeptide in sensory and autonomic ganglia and in spinal cord of the rat. J Comp Neurol 394:403-415

42. Tajti J, Uddman R, Moller S, Sundler F, Edvinsson L (1999) Messenger molecules and receptor mRNA in the human trigeminal ganglion. J Auton Nerv Syst 76:176-183

43. Hou M, Uddman R, Tajti J, Edvinsson L (2003) Nociceptin immunoreactivity and receptor mRNA in the human trigeminal ganglion. Brain Res 964:179-186

44. Eftekhari S, Salvatore CA, Johansson S, Chen TB, Zeng Z, Edvinsson L (2015) Localization of CGRP, CGRP receptor, PACAP and glutamate in trigeminal ganglion. Relation to the blood-brain barrier. Brain Res 1600:93-109

45. Uddman R, Tajti J, Hou M, Sundler F, Edvinsson L (2002) Neuropeptide expression in the human trigeminal nucleus caudalis and in the cervical spinal cord C1 and C2. Cephalalgia 22:112-116

46. Tajti J, Uddman R, Edvinsson L (2001) Neuropeptide localization in the "migraine generator" region of the human brainstem. Cephalalgia 21:96-101

47. Legradi G, Shioda S, Arimura A (1994) Pituitary adenylate cyclase-activating polypeptide-like immunoreactivity in autonomic regulatory areas of the rat medulla oblongata. Neurosci Lett 176:193-196

48. Uddman R, Tajti J, Moller S, Sundler F, Edvinsson L (1999) Neuronal messengers and peptide receptors in the human sphenopalatine and otic ganglia. Brain Res 826:193-199

49. Csati A, Tajti J, Kuris A, Tuka B, Edvinsson L, Warfvinge K (2012) Distribution of vasoactive intestinal peptide, pituitary adenylate cyclase-activating peptide, nitric oxide synthase, and their receptors in human and rat sphenopalatine ganglion. Neuroscience 202:158-168

50. Steinberg A, Frederiksen SD, Blixt FW, Warfvinge K, Edvinsson L (2016) Expression of messenger molecules and receptors in rat and human sphenopalatine ganglion indicating therapeutic targets. J Headache Pain 17:78

51. Mulder H, Uddman R, Moller K, Zhang YZ, Ekblad E, Alumets J, Sundler F (1994) Pituitary adenylate cyclase activating polypeptide expression in sensory neurons. Neuroscience 63:307-312

52. Edvinsson L, Uddman R (2005) Neurobiology in primary headaches. Brain Res Brain Res Rev 48:438-456

53. Cauvin A, Robberecht $P$, De Neef $P$, Gourlet $P$, Vandermeers $A$, Vandermeers-Piret MC, Christophe J (1991) Properties and distribution of receptors for pituitary adenylate cyclase activating peptide (PACAP) in rat brain and spinal cord. Regul Pept 35:161-173

54. Suda K, Smith DM, Ghatei MA, Murphy JK, Bloom SR (1991) Investigation and characterization of receptors for pituitary adenylate cyclase-activating polypeptide in human brain by radioligand binding and chemical crosslinking. J Clin Endocrinol Metab 72:958-964

55. Chaudhary P, Baumann TK (2002) Expression of VPAC2 receptor and PAC1 receptor splice variants in the trigeminal ganglion of the adult rat. Brain Res Mol Brain Res 104:137-142

56. Saghy E, Payrits M, Helyes Z, Reglodi D, Banki E, Toth G, Couvineau A, Szoke E (2015) Stimulatory effect of pituitary adenylate cyclase-activating polypeptide $6-38, \mathrm{M} 65$ and vasoactive intestinal polypeptide 6-28 on trigeminal sensory neurons. Neuroscience 308:144-156

57. Knutsson M, Edvinsson L (2002) Distribution of mRNA for VP and PACAP receptors in human cerebral arteries and cranial ganglia. Neuroreport 13:507-509

58. Goadsby PJ, Edvinsson L (1994) Human in vivo evidence for trigeminovascular activation in cluster headache. Neuropeptide changes and effects of acute attacks therapies. Brain 117(Pt 3):427-434

59. Goadsby PJ, Edvinsson L (1994) Joint 1994 Wolff award presentation. Peripheral and central trigeminovascular activation in cat is blocked by the serotonin (5HT)-1D receptor agonist 311C90. Headache 34:394-399

60. Schytz HW, Birk S, Wienecke T, Kruuse C, Olesen J, Ashina M (2009) PACAP38 induces migraine-like attacks in patients with migraine without aura. Brain 132:16-25

61. Olesen J, Iversen HK, Thomsen LL (1993) Nitric oxide supersensitivity: a possible molecular mechanism of migraine pain. Neuroreport 4:1027-1030

62. Sicuteri F, Del Bene E, Poggioni M, Bonazzi A (1987) Unmasking latent dysnociception in healthy subjects. Headache 27:180-185

63. Lassen LH, Haderslev PA, Jacobsen VB, Iversen HK, Sperling B, Olesen J (2002) CGRP may play a causative role in migraine. Cephalalgia 22:54-61

64. Amin FM, Asghar MS, Guo S, Hougaard A, Hansen AE, Schytz HW, van der Geest RJ, de Koning PJ, Larsson HB, Olesen J, Ashina M (2012) Headache and prolonged dilatation of the middle meningeal artery by PACAP38 in healthy volunteers. Cephalalgia 32:140-149

65. Amin FM, Hougaard A, Schytz HW, Asghar MS, Lundholm E, Parvaiz Al, de Koning PJ, Andersen MR, Larsson HB, Fahrenkrug J, Olesen J, Ashina M (2014) Investigation of the pathophysiological mechanisms of migraine attacks induced by pituitary adenylate cyclase-activating polypeptide-38. Brain 137:779-794

66. Amin FM, Hougaard A, Magon S, Asghar MS, Ahmad NN, Rostrup E, Sprenger T, Ashina M (2016) Change in brain network connectivity during PACAP38-induced migraine attacks: a resting-state functional MRI study. Neurology 86:180-187

67. Guo S, Vollesen AL, Hansen YB, Frandsen E, Andersen MR, Amin FM, Fahrenkrug J, Olesen J, Ashina M (2016) Part II: biochemical changes after pituitary adenylate cyclase-activating polypeptide-38 infusion in migraine patients. Cephalalgia

68. Guo S, Vollesen AL, Hansen RD, Esserlind AL, Amin FM, Christensen AF, Olesen J, Ashina M (2016) Part I: pituitary adenylate cyclase-activating polypeptide-38 induced migraine-like attacks in patients with and without familial aggregation of migraine. Cephalalgia

69. Zhang YZ, Sjolund B, Moller K, Hakanson R, Sundler F (1993) Pituitary adenylate cyclase activating peptide produces a marked and longlasting depression of a C-fibre-evoked flexion reflex. Neuroscience 57: 733-737

70. Narita M, Dun SL, Dun NJ, Tseng LF (1996) Hyperalgesia induced by pituitary adenylate cyclase-activating polypeptide in the mouse spinal cord. Eur J Pharmacol 311:121-126

71. Davis-Taber R, Baker S, Lehto SG, Zhong C, Surowy CS, Faltynek CR, Scott VE, Honore P (2008) Central pituitary adenylate cyclase 1 receptors modulate nociceptive behaviors in both inflammatory and neuropathic pain states. J Pain 9:449-456

72. Jongsma H, Pettersson LM, Zhang Y, Reimer MK, Kanje M, Waldenstrom A, Sundler F, Danielsen N (2001) Markedly reduced chronic nociceptive response in mice lacking the PAC1 receptor. Neuroreport 12:2215-2219

73. Mabuchi T, Shintani N, Matsumura S, Okuda-Ashitaka E, Hashimoto H, Muratani T, Minami T, Baba A, Ito S (2004) Pituitary adenylate cyclase-activating polypeptide is required for the development of spinal sensitization and induction of neuropathic pain. J Neurosci 24:7283-7291

74. Markovics A, Kormos V, Gaszner B, Lashgarara A, Szoke E, Sandor K, Szabadfi K, Tuka B, Tajti J, Szolcsanyi J, Pinter E, Hashimoto H, Kun J, Reglodi D, Helyes Z (2012) Pituitary adenylate cyclase-activating polypeptide plays a 
key role in nitroglycerol-induced trigeminovascular activation in mice. Neurobiol Dis 45:633-644

75. Martin M, Otto C, Santamarta MT, Torrecilla M, Pineda J, Schutz G, Maldonado R (2003) Morphine withdrawal is modified in pituitary adenylate cyclase-activating polypeptide type I-receptor-deficient mice. Brain Res Mol Brain Res 110:109-118

76. Missig G, Roman CW, Vizzard MA, Braas KM, Hammack SE, May V (2014) Parabrachial nucleus (PBn) pituitary adenylate cyclase activating polypeptide (PACAP) signaling in the amygdala: implication for the sensory and behavioral effects of pain. Neuropharmacology 86:38-48

77. Akerman S, Goadsby PJ (2015) Neuronal PAC1 receptors mediate delayed activation and sensitization of trigeminocervical neurons: relevance to migraine. Sci Transl Med 7:308ra157

78. Sandor K, Bolcskei K, McDougall JJ, Schuelert N, Reglodi D, Elekes K, Petho G, Pinter E, Szolcsanyi J, Helyes Z (2009) Divergent peripheral effects of pituitary adenylate cyclase-activating polypeptide-38 on nociception in rats and mice. Pain 141:143-150

79. Helyes Z, Pozsgai G, Borzsei R, Nemeth J, Bagoly T, Mark L, Pinter E, Toth G, Elekes K, Szolcsanyi J, Reglodi D (2007) Inhibitory effect of PACAP-38 on acute neurogenic and non-neurogenic inflammatory processes in the rat. Peptides 28:1847-1855

80. Nemeth J, Reglodi D, Pozsgai G, Szabo A, Elekes K, Pinter E, Szolcsanyi J, Helyes Z (2006) Effect of pituitary adenylate cyclase activating polypeptide38 on sensory neuropeptide release and neurogenic inflammation in rats and mice. Neuroscience 143:223-230

81. Zhang Y, Malmberg AB, Sjolund B, Yaksh TL (1996) The effect of pituitary adenylate cyclase activating peptide (PACAP) on the nociceptive formalin test. Neurosci Lett 207:187-190

82. Baun M, Pedersen MH, Olesen J, Jansen-Olesen I (2012) Dural mast cell degranulation is a putative mechanism for headache induced by PACAP-38. Cephalalgia 32:337-345

83. Bhatt DK, Gupta S, Olesen J, Jansen-Olesen I (2014) PACAP-38 infusion causes sustained vasodilation of the middle meningeal artery in the rat: possible involvement of mast cells. Cephalalgia 34:877-886

84. Mori T, Kawashima T, Beppu Y, Takagi K (1994) Histamine release induced by pituitary adenylate cyclase activating polypeptide from rat peritoneal mast cells. Arzneimittelforschung 44:1044-1046

85. Odum L, Petersen $\sqcup$, Skov PS, Ebskov LB (1998) Pituitary adenylate cyclase activating polypeptide (PACAP) is localized in human dermal neurons and causes histamine release from skin mast cells. Inflamm Res 47:488-492

86. Schytz HW (2010) Investigation of carbachol and PACAP38 in a human model of migraine. Dan Med Bull 57:B4223

87. Zhang Y, Malmberg AB, Yaksh TL, Sjolund B, Sundler F, Hakanson R (1997) Capsaicin-evoked release of pituitary adenylate cyclase activating peptide (PACAP) and calcitonin gene-related peptide (CGRP) from rat spinal cord in vivo. Regul Pept 69:83-87

88. Tuka B, Helyes Z, Markovics A, Bagoly T, Nemeth J, Mark L, Brubel R, Reglodi D, Pardutz A, Szolcsanyi J, Vecsei L, Tajti J (2012) Peripheral and central alterations of pituitary adenylate cyclase activating polypeptide-like immunoreactivity in the rat in response to activation of the trigeminovascular system. Peptides 33:307-316

89. Zagami AS, Edvinsson L, Goadsby PJ (2014) Pituitary adenylate cyclase activating polypeptide and migraine. Ann Clin Transl Neurol 1:1036-1040

90. Zagami AS, Goadsby PJ, Edvinsson L (1990) Stimulation of the superior sagittal sinus in the cat causes release of vasoactive peptides. Neuropeptides 16:69-75

91. Tuka B, Helyes Z, Markovics A, Bagoly T, Szolcsanyi J, Szabo N, Toth E, Kincses ZT, Vecsei L, Tajti J (2013) Alterations in PACAP-38-like immunoreactivity in the plasma during ictal and interictal periods of migraine patients. Cephalalgia 33:1085-1095

92. Tuka B, Szabo N, Toth E, Kincses ZT, Pardutz A, Szok D, Kortesi T, Bagoly T, Helyes Z, Edvinsson L, Vecsei L, Tajti J (2016) Release of PACAP-38 in episodic cluster headache patients - an exploratory study. J Headache Pain 17:69

93. Han X, Dong Z, Hou L, Wan D, Chen M, Tang W, Yu S (2015) Interictal plasma pituitary adenylate cyclase-activating polypeptide levels are decreased in migraineurs but remain unchanged in patients with tensiontype headache. Clin Chim Acta 450:151-154

94. Zagami AS, Edvinsson L, Hoskin KL, Goadsby PJ (1995) Stimulation of the superior sagittal sinus causes extracranial release of PACAP. Cephalalgia 15(Suppl 14):109
95. Reglodi D, Tamas A (2016) Pituitary Adenylate Cyclase activating polypeptide - PACAP. Cham. Springer International Publishing

96. Erdling A, Sheykhzade M, Maddahi A, Bari F, Edvinsson L (2013) VIP/PACAP receptors in cerebral arteries of rat: characterization, localization and relation to intracellular calcium. Neuropeptides 47:85-92

97. Syed AU, Koide M, Braas KM, May V, Wellman GC (2012) Pituitary adenylate cyclase-activating polypeptide (PACAP) potently dilates middle meningeal arteries: implications for migraine. J Mol Neurosci 48:574-583

\section{Submit your manuscript to a SpringerOpen ${ }^{\circ}$ journal and benefit from:}

- Convenient online submission

- Rigorous peer review

- Open access: articles freely available online

- High visibility within the field

- Retaining the copyright to your article

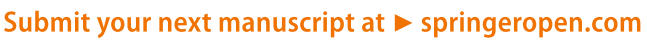

